\section{Por um Olhar Inverso: prismas e questões de pesquisa sobre a Economia Solidária*}

Luiz Inácio Germany Gaiger ${ }^{1}$

Resumo: A Economia Solidária constitui hoje um tema de pesquisa cuja expansão em várias disciplinas vizinhas à Sociologia é nítida e profícua. Nesse contexto, e tendo em vista as novas alternativas de investigação propiciadas pelo "Mapeamento Nacional da Economia Solidária no Brasil", o artigo discute algumas frentes de trabalho ainda merecedoras de investigação e consolidação teórica, no âmbito do que considera como pauta de pesquisa já em evidência. A seguir, chama atenção para aspectos do padrão de pesquisa vigente nesse campo, uma vez que seu entrelaçamento com a práxis política da Economia Solidária tende a resultar em renúncias a tratar determinados problemas e em lacunas de conhecimento. Diante disso, propõe bases para um delineamento investigativo com maior amplitude cognitiva, em especial no sentido de reconhecer os fatores primordiais de impulsão da Economia Solidária e a sua irredutibilidade ao econômico.

Palavras-chave: Autogestão, Economia Popular, Reciprocidade, Solidariedade, Pierre Bourdieu.

\section{Introdução}

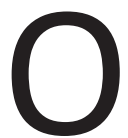

termo Economia Solidária tem servido para designar um conjunto amplo de práticas coletivas, que, embora multiformes, mostram-se irredutíveis ou mesmo antagônicas à lógica utilitária do interesse próprio que estrutura a atual economia de mercado e fundamenta o paradigma neoclássico acerca do agir econômico e da vida em sociedade (GODBOUT, 1999). A Economia Solidária, sendo relacionada a iniciativas participativas e cooperativas, decorrentes da associação voluntária entre trabalhadores, consumidores e cidadãos engajados em questões de interesse comum, enfatiza a presença de condutas fundadas em relações de reciprocidade, orientadas precipuamente à preservação do vínculo social (GAIGER, 2008).

O entendimento das formas contemporâneas de solidariedade comporta distintas ênfases e abordagens, em relação aos seus sentidos e dimensões (Sociedade \& Estado, 2001; CATTANI et al., 2009). Com suas expressões ao Sul e ao Norte, notadamente as práticas de solidariedade socioeconômica se têm
Recebido:

19.06.11

Aprovado:

14.05.12

1. Programa de PósGraduação em Ciências Sociais UNISINOS - Brasil E-mail: gaiger@unisinos.br

* Artigo relacionado à pesquisa com financiamento do CNPq. 
convertido em um campo de estudos para as ciências sociais, constando em pesquisas e debates sobre novas experiências sociais e suas virtudes emancipadoras. Em eventos de abrangência nacional e internacional, essas iniciativas têm sido tratadas com frequência, figurando já na agenda corrente de centros de pesquisa e pós-graduação. Seu interesse passou a ser reconhecido por agências fomentadoras e órgãos avaliadores, viabilizando estudos mais abrangentes e propiciando iniciativas de cooperação internacional. Multiplicam-se redes de pesquisa e práticas de mobilidade docente e discente, somadas a ações de colaboração com instituições privadas e públicas atuantes no campo.

Há indicadores do crescimento da produção acadêmica sobre a Economia Solidária, tais como a evolução temática dos Grupos de Pesquisa no Diretório do CNPq (entre 2009 e 2011, o número de Grupos vinculados à Economia Solidária elevou-se de 92 para 130) ou o banco de currículos Lattes (5.508 pesquisadores declinam o tema, dos quais 1.708 são doutores e 196, Bolsistas de Produtividade - dados de março/2012). O mais sugestivo, no entanto, é o crescimento exponencial das teses e dissertações registradas pela CAPES com referência à Economia Solidária: de 36, no quinquênio 1996-2000, passaram a 195 no período posterior, até 2005, e a 404, nos últimos cinco anos (2006-2011).

Nesse artigo, tem-se em vista, particularmente, essa nova geração de pesquisadores, no intuito de apontar alguns problemas a que se expõem as práticas de pesquisa desenvolvidas nas condições atuais. Tais apontamentos são feitos, mais precisamente, em atenção ao fato de que o campo acadêmico voltado à Economia Solidária se notabiliza por um trânsito intenso entre a sociedade civil, a institucionalidade política e o aparelho de Estado, produzindo um espaço de circulação e confluência em que se formulam e executam políticas públicas e se constitui a agenda central dos debates e mobilizações. O fato repercute nos itinerários individuais, sob a forma de uma alternância de espaços institucionais e de funções ocupadas pelas pessoas envolvidas com a Economia Solidária: ora como assessores de ONGs, ora como pesquisadores, ora como agentes públicos, ora ainda como militantes ou integrantes de iniciativas solidárias de organização social e econômica.

Nessas circunstâncias, uma questão de fundo diz respeito à observância do preceito basilar de vigilância epistemológica, legado com justificada insistência por Pierre Bourdieu: a cientificidade pressupõe uma tomada de consciência permanente do que, na construção do objeto de pesquisa e nos processos de investigação em que o mesmo se desdobra, deve-se precipuamente à condição e à posição social do pesquisador. A exigência consiste em romper com as visões construídas do mundo social e, também, com a atitude espontânea de adotar as categorias de entendimento colocadas em nossas mãos pela doxa científica. $\mathrm{Na}$ falta dessa reflexão da prática científica sobre si mesma, a tendência é que 
cesse de se interrogar sobre o que deixa de reconhecer e apreender da realidade. Não seria despropositado supor que essa inclinação conformista tenha mais chances de tornar-se imperceptível e insidiosa em contextos de emulação ideológica, quando estão em jogo grandes causas, já que a crítica em tais momentos, indispensável à defesa de posições - por vezes, também ao autoconvencimento -, no calor do debate e no fremir das ações, pode ficar involuntariamente desprovida de suficiente espírito crítico.

A multiplicidade das pesquisas de desafios correlatos como esse enseja os objetivos e a estrutura do artigo. Em primeiro lugar, apresentar como se perfila, hoje, a Economia Solidária, reconhecendo seus antecedentes históricos e como se converte em objeto de pesquisa e de envolvimento acadêmico (seção 1). Em segundo lugar, no âmbito do que se considera a agenda de pesquisa já em evidência neste campo, pontuar algumas frentes de trabalho ainda merecedoras de investigação e consolidação teórica (seção 2). Em terceiro lugar, tecer alguns questionamentos ao padrão de pesquisa vigente no campo, à medida que seu entrelaçamento com a práxis social da Economia Solidária o expõe ao risco da incorporação irrefletida dos prismas e hierarquias de problemas, tal qual emanados da agenda e do campo da ação, o que, por consequência, o sujeita a incorrer em renúncias de conhecimento (seção 3). Enfim, ao longo do texto e ao seu final (seção 4), indicar vias suscetíveis de conduzir a delineamentos investigativos de maior amplitude cognitiva. Ao final do texto, destacam-se os principais dimensionamentos propostos no sentido de inversões do olhar corrente sobre a Economia Solidária.

O tratamento proposto para esses temas não deve ser identificado com uma revisão bibliográfica do estado da arte sobre a Economia Solidária, ou com um inventário de alternativas de investigação, um assunto vasto já abordado parcialmente (GAIGER, 2011). Trata-se, antes, de uma análise crítica e propositiva, favorecida pela inserção contínua do autor nesse campo de pesquisa, desde 1992, e, principalmente, pelo acompanhamento das trajetórias de um bom número de pesquisadores - no geral, jovens em formação - atraídos pela novidade da Economia Solidária, especialmente pelas teses sobre suas potencialidades transformadoras. A observação desses percursos tem-se dado graças às atividades de docência e orientação, em várias instituições, à participação em projetos nacionais de pesquisa e à organização ou coordenação periódica de eventos e encontros, entre eles, grupos de trabalho de nossas sociedades científicas. A direção de redes de pesquisa e de revistas científicas propicia também uma fonte valiosa de informações. Tem sido igualmente providencial a presença, nos espaços de mobilização e discussão política da Economia Solidária, em representação de redes acadêmicas, em trabalhos de consultoria a órgãos do Estado ou na execução de projetos de pesquisas em 
consórcio com entidades civis ou públicas. Nesse último caso, cabe ressaltar que o Grupo de Pesquisa, liderado pelo autor deste artigo, tem participado da concepção, execução e análise dos dados do Mapeamento Nacional da Economia Solidária, cuja pertinência para a discussão aqui proposta será justificada adiante.

\section{A Economia Solidária como Prática e como Objeto de Conhecimento}

Os princípios da Economia Solidária manifestam-se desde a instauração do capitalismo industrial, havendo impulsionado as vertentes associativas, mutualistas e cooperativas nas quais se edificou a experiência da Economia Social no correr do século XIX, em vários países do Norte e em alguns países do Sul. Naquele contexto, diante da turbulência social causada pela revolução industrial, o associativismo surgiu como uma resposta de trabalhadores submetidos à proletarização, caracterizando-se, desde esses primórdios, por suas formas de gestão autônomas e participativas. Em tais iniciativas, as relações de poder e a repartição dos ganhos subordinavam-se ao primado das pessoas diante do capital e à finalidade precípua de garantir benefícios aos membros (PETITCLERC, 2007).

Até mostrar sinais de debilitamento, já no limiar do século XX, a Economia Social desenvolveu organizações cujo traço distintivo foi combinar recursos provenientes do mercado, oriundos da venda e troca de bens e serviços, com recursos de natureza não mercantil, como as subvenções públicas e, ainda, com recursos externos à lógica monetária, como as práticas de entreajuda. A Economia Social se opôs às tendências de redução da economia ao princípio do mercado e à racionalidade da acumulação privada; com tais premissas, desempenhou um papel considerável na construção dos regimes do bem-estar social. No entanto, à medida que o mercado e o Estado foram assumindo suas funções de geração de riqueza e de assistência social, a solidariedade de tipo associativo recuou para um papel subsidiário, de sorte que a institucionalização da Economia Social terminou por engendrar, contraditoriamente, sua fragmentação e sua perda de identidade (DEFOURNY et al., 1999).

A partir dos anos 1970, com a crise de regulação keynesiana repercutindo diretamente sobre as funções de preservação do equilíbrio social típicas do Estado Providência, uma série de novas experimentações passou a ter lugar (LAVILLE \& GAIGER, 2009). Frente ao domínio de políticas direcionadas a ampliar a liberdade do capital em suas novas formas, princípios e práticas de solidariedade econômica readquiriram vigor e atualidade, haja vista a incapacidade do sistema dominante em evitar crises cíclicas e em conjurar situações de dependência, desigualdade e insegurança social. A Economia Social, na Europa, 
retomou seu elã crítico e participativo, atenuado durante a vigência do Estado do Bem-Estar, ao mesmo tempo em que experiências análogas surgiram ou se revitalizaram em países do Sul, em particular na América Latina. Associações, grupos informais, cooperativas, empresas de autogestão, iniciativas locais no campo dos serviços sociais e de assistência a pessoas necessitadas, empresas sociais, finanças solidárias, comércio justo, além de mecanismos correlatos de fomento e organizações representativas, expandiram-se entre aqueles setores sociais à margem dos sistemas convencionais de ocupação e renda, ou crescentemente frustrados em suas aspirações individuais e coletivas. Justificou-se, assim, a menção a uma nova Economia Social, a seguir designada de Economia Solidária, em boa parte da Europa e da América do Sul.

As manifestações concretas da vigência de princípios solidários, na economia e na vida coletiva, variam com os seus protagonistas. Com denominações ligeiramente distintas - Economia Social e/ou Solidária - sua expansão atualmente é verificada ao Sul e ao Norte, bem como suas conexões com novos movimentos sociais e sua presença nas mobilizações altermundialistas (DEFOURNY et al., 1999; MENDELL, 2003; CATTANI et al., 2009; FONTENEAU, 2011). Alinham-se a uma gama ampla e heterogênea de iniciativas, como as lutas por direitos, os movimentos humanitários, o ambientalismo, as políticas de responsabilidade social e os bancos éticos. Embora seu surgimento, propagação e institucionalização ocorram em contextos dessemelhantes, a Economia Solidária demonstraria considerável unidade normativa e política, graças à progressiva confluência de suas agendas e pautas de mobilização, do plano local ao global².

Na América Latina, o conceito de Economia Solidária refere-se, comumente, a iniciativas econômicas que visam à geração de trabalho e renda, além de benefícios como qualidade de vida, reconhecimento e participação cidadã. A solidariedade diz respeito à cooperação na atividade produtiva, à disponibilização para uso em comum dos meios de produção e à autogestão exercida na condução dos empreendimentos. As organizações de Economia Solidária minimizam a presença de relações sociais que subentendem a separação entre capital e trabaIho. Como seria de se esperar, compõem um quadro multiforme no continente.

No Brasil, a principal referência empírica disponível a seu respeito é o SIES - Sistema Nacional de Informações de Economia Solidária, alimentado pelo primeiro Mapeamento Nacional, concluído em 2007. Como traços gerais, constata-se que os 22 mil empreendimentos recenseados se dividem em duas categorias principais: a) aqueles cuja atividade constitui a fonte primordial de ocupação e de renda dos seus integrantes, desenvolvendo-se através de processos de socialização dos meios de produção ou de coletivização do trabalho. Abrangem grupos informais de produção, cooperativas agropecuárias e de trabalho,
2. Essa última assertiva, se, politicamente, é considerada um dado de realidade, do ponto de vista analítico constituiria, antes, uma das hipóteses e fontes de problematização a balizarem os estudos nessa área. 
empresas recuperadas, unidades de triagem de resíduos urbanos recicláveis e comunidades tradicionais, como pescadores e extrativistas; b) aqueles cuja atividade coletiva aporta benefícios e serviços para as economias individuais ou familiares dos seus integrantes. Compreendem as associações de pequenos produtores rurais, centrais de comercialização, cooperativas de habitação, eletrificação e crédito, bancos populares, clubes de troca e hortas comunitárias.

Até meados dos anos 1990, o caráter aparentemente circunstancial e efêmero das práticas posteriormente identificadas com a Economia Solidária deixou-a ao largo da produção acadêmica, bem como dos temas centrais em discussão no âmbito das políticas públicas. Os primeiros estudos sobre essas experiências foram promovidos por entidades de apoio, em alguns casos, em parceria com universidades, tendo seus resultados circulado em boletins, revistas de divulgação e livros, antes de integrarem a produção acadêmica em sentido estrito. O interesse investigativo pelo tema despertou, a princípio, em instituições de pesquisa já dedicadas ao estudo do associativismo e do cooperativismo, ao lado de universidades envolvidas com projetos de incubadoras de cooperativas populares, gradativamente articulados à pesquisa e à docência. Nos dias atuais, a pesquisa sobre a Economia Solidária reveste-se de características acadêmicas, apresentando-se de forma interdisciplinar e integrada a estudos em temáticas afins ou sobre questões mais gerais das sociedades e da realidade global.

Contudo, uma simbiose singular entre reflexão e ação marca a atuação das instituições especializadas, pois a atividade científica sobre a Economia Solidária não se cinge ao interior dos recintos universitários, bem ao contrário. Quem se dedica ao tema, além de atribuições típicas como a docência, a pesquisa e a orientação de trabalhos acadêmicos, usualmente colabora em programas de apoio às experiências solidárias e participa dos circuitos de debate, quando não de instâncias deliberativas ou de articulação política. As pesquisas desenvolvemse, via de regra, em conexão com demandas provenientes dos atores sociais, sendo comum seu vínculo com programas públicos que estimulam ou financiam estudos e avaliações. De parte do Estado, o fato de que a Secretaria Nacional de Economia Solidária disponha de um Departamento de Estudos e Divulgação traduz um reconhecimento quanto ao valor da produção de conhecimentos, por meio de levantamentos de dados, estudos e análises. Essas relações entre práticas sociais, políticas públicas e conhecimentos não passaram despercebidas às primeiras revisões da literatura acadêmica sobre a Economia Solidária (LEITE, 2009; GAIGER, 2011; LIMA, 2012), que registram as mútuas influências entre ciência, política e ideologia, constitutivas dessa área de conhecimento.

As indicações feitas ao longo desse texto inspiram-se e encontram um suporte empírico preponderante em um dos resultados mais significativos da 
cooperação entre o poder público, as organizações civis, os movimentos sociais e o campo acadêmico: o SIES, já citado, e o processo nacional de Mapeamento dos empreendimentos solidários que lhe deu origem. $\mathrm{O}$ trabalho de identificar e caracterizar os empreendimentos, adentrando zonas rurais e áreas remotas do território nacional, motivou o envolvimento de mais de 230 entidades e a ida a campo de 600 técnicos e entrevistadores, entre 2003 e 2007, até a crítica e validação dos dados ${ }^{3}$.

O mapeamento cobriu iniciativas que tivessem cinco características: a) constituírem organizações suprafamiliares permanentes; b) sob a propriedade ou controle dos sócios-trabalhadores; c) com emprego ocasional e minoritário de trabalhadores não associados; d) com gestão coletiva das suas atividades e da alocação dos resultados; e) de natureza econômica, direcionada à produção, comercialização, serviços, crédito ou consumo. Não obstante todas as dificuldades imagináveis em um levantamento inédito de informações, o mapeamento abarcou um número significativo de empreendimentos, constituindo-se então como um levantamento expressivamente representativo da Economia Solidária.

O porte dos empreendimentos, suas formas de organização e os setores econômicos nos quais atuam são diversos. Para uma caracterização geral muito breve: $51,8 \%$ deles são associações; $36,5 \%$, grupos informais; $9,7 \%$, cooperativas. As atividades coletivas mais frequentes são a produção $(63,3 \%)$, a comercialização $(59,6 \%)$ e o uso de equipamentos produtivos $(49,9 \%)$. Dedicam-se à agricultura, pecuária, pesca ou extrativismo, 54,9\% dos empreendimentos, os demais se dividindo entre a produção e a prestação de serviços em setores de alimentação, confecções e calçados, artesanato, indústria de transformação, coleta e reciclagem e, ainda, crédito e finanças. Quanto ao porte, 24\% possuem até 30 sócios, enquanto no extremo oposto registram-se 370 casos $(1,7 \%)$ com mais de 500 associados. Ao redor de 19,7\% possuem menos de seis sócios trabalhando regularmente no empreendimento e 59,3\% possuem até 30 trabalhadores dentro do seu quadro social.

As referências ao mapeamento objetivam estimular sua utilização, pois, até o momento, esse acervo de dados tem sido pouco explorado, descuidando-se do valor metodológico e epistemológico implícito nesse esforço de cartografar a Economia Solidária. Tenciona-se também chamar a atenção ao novo manancial de informações que - de forma similar - deverá estar à disposição em meados de 2012, ao término do segundo Mapeamento Nacional, cujo formato, aperfeiçoado graças à experiência anterior, apresenta indicadores de maior abrangência e precisão para a coleta das informações. Tenciona-se cobrir todos os municípios do país e coletar informações de 30 mil empreendimentos. Visto ser possível cruzar tais dados com os resultados do primeiro mapeamento, abrem-se possibilidades interessantes de análise diacrônica, dado o lapso de
3. O trabalho final foi realizado pela Secretaria Nacional de Economia Solidária, o Instituto de Pesquisas Econômicas Aplicadas (IPEA) e a Universidade do Vale do Rio dos Sinos. A base conceitual e a metodologia do Mapeamento, incluindo a capacitação dos entrevistadores e a consolidação dos dados, constam dos documentos de referência disponíveis em www.sies.mte. gov.br, além dos dados agregados $\mathrm{e}$ dos dispositivos de acesso aos microdados. 
tempo entre os dois processos de coleta.

\section{Temáticas em Evidência}

Uma das principais questões de fundo em debate diz respeito aos espaços efetivos deixados hoje a tais formas de organização do trabalho e das atividades econômicas. As determinações da ordem econômica, com seus processos flexíveis de acumulação, se valem precisamente de formas não tipicamente capitalistas de produção e retiram de foco a perspectiva universalista e igualitarista da solidariedade redistributiva, outrora delegada ao Estado. Ainda que se descartem liminarmente os artifícios destinados a explorar o trabalho por meio de cooperativas fraudulentas, de fachada, não se deveriam negligenciar os riscos de distorção e de retrocesso que pairam sobre as iniciativas genuinamente conduzidas pelos trabalhadores, confrontadas à força das pressões externas e às dificuldades inerentes ao ato associativo. Cabe, então, dar continuidade aos estudos sobre as condições gerais prévias necessárias à formação dessas experiências e sobre as vias mais propícias à sua preservação e desenvolvimento.

Com esse propósito, um preâmbulo habitual ao entendimento das formas de Economia Solidária, sobretudo quando se têm em mente setores às voltas com sua sobrevivência imediata, consiste em deter-se sobre as transformações do mercado e das relações de trabalho. Tais análises contextualizam a Economia Solidária e neutralizam a compreensível carga de idealização dos discursos produzidos por seus protagonistas e apoiadores. Mas não basta às análises constatarem as circunstâncias que, à revelia e a contragosto dos trabalhadores, os compelem a buscar alternativas de ocupação e renda, como se a existência dessas pressões bastasse para conduzi-los em uma determinada direção, tanto mais se inteiramente nova para alguns e, a princípio, incerta para todos, como estampado pela via associativa. As determinações estruturais não explicam escolhas não convencionais de modo independente dos valores, das formas de sociabilidade e dos novos fatos gerados pelos atores sociais em questão. Entre a precarização, ou a pauperização, e as lutas sociais, há uma produção de experiências, cujo percurso e desenlace não se encerram no quadro das condições objetivas. A subjetividade - ou a identidade forjada na nova trajetória de trabaIho e nos envolvimentos coletivos - ao produzir sentidos para o ator, o impulsiona à ação e contribui decisivamente para o significado social ao alcance dessas experiências. Daí ser bem-vinda a geração de estudos interdisciplinares sobre a Economia Solidária, com lastro na Psicologia, na Semiótica e na Antropologia, além das áreas mais tradicionais, como a Sociologia, a Educação e a Economia.

A investigação sobre formas alternativas supõe a hipótese de que outras 
lógicas possam funcionar no tecido social, para além do cânone capitalista da produção e circulação de bens. Teoricamente, implica desfazer a noção do mercado como um regulador geral abstrato e autossuficiente e entendê-lo como um espaço de trocas inserido em um sistema plural de regulação e arbitragens, determinado igualmente por fatores não econômicos (POLANYI, 1988). Significa reconhecer práticas econômicas vincadas em princípios não utilitaristas, virtualmente portadoras de sociabilidades densas em comparação com os vínculos contratuais do mercado, além de decisivas para a sobrevivência de inúmeros indivíduos e segmentos sociais. A partir da Sociologia e da Antropologia Econômica, é valioso seguir investigando em que medida as iniciativas de Economia Solidária orientam-se por uma racionalidade híbrida, irredutível à maximização do interesse próprio (PINTO, 2006; FERRARINI \& GAIGER, 2010).

A dimensão comunitária e social dessas organizações as inclina ao envolvimento de seus integrantes em questões de interesse público, estimulando formas variadas de mobilização. De outra parte, um número expressivo de experiências apenas se explica pelo suporte de organizações vinculadas ao movimento sindical, rural e urbano, fortalecendo, com isso, as bandeiras históricas de autogestão e de emancipação econômica dos trabalhadores. A diversidade de mobilizações acentuou-se, sem impedir processos de mútuo reconhecimento e de progressiva unificação política em torno de uma plataforma comum e de dispositivos de representação.

Por conseguinte, importa trazer à baila a questão democrática no Brasil, no sentido de contribuir ao entendimento das intersecções entre a participação popular e a institucionalidade política. Retomando a importante questão de Doimo (1995), as mobilizações populares identificadas como a solidariedade, por sua capacidade de gerar confluências a partir da diversidade, ou de formar consensos em torno de novos itens da agenda pública, não estariam realimentando um ethos movimentalista, que predispõe os indivíduos à participação? Estaria a Economia Solidária cumprindo o papel de galvanizar as lutas cidadãs no período posterior à transição democrática? Sendo assim, quais os riscos de contenção dessa dinâmica, em consequência de sua inserção nos circuitos reprodutivos que caracterizam a institucionalidade política? $\mathrm{O}$ tema vem sendo abordado (CARNEIRO, 2006; SANTOS, 2010; MIRANDA, 2011), também de nossa parte (GAIGER, 2012), mas carece de lugar mais destacado na agenda de pesquisas, de modo que se compreenda o significado da Economia Solidária para a política e a consolidação democrática do país.

No horizonte que atualmente se descortina, não existem práticas e modelos alternativos portadores de uma nova totalidade, em ruptura plena com as determinações atuais. Há, sim, formas de existência individual e coletiva que escapam ao sistema social capitalista e de cuja força emancipatória novos cenários 
podem advir no futuro. Posto nesses termos, o problema tem conduzido a reflexão em dois sentidos. De um lado, à análise dos caminhos por que avança a economia e o sistema político mundial, no contexto da globalização. No campo específico da Economia Solidária, trabalhos de teorização geral levaram a formulações seminais quanto à originalidade por ela representada (RAZETO, 1997) ou ao fato de ser uma expressão revigorada das utopias políticas do movimento socialista (SINGER, 1999). Em paralelo, sucedem-se estudos sobre as condições em que os empreendimentos solidários se desenvolvem e prosperam, dando eco a uma literatura apreciável sobre a cooperação produtiva (ROSTHSCHILD \& WHITT 1986; DEFOURNY, 1988; COUTROT, 1999) e sobre as formas mais adequadas à sua promoção, tema em que se têm salientado, no Brasil, as discussões sobre as tecnologias sociais (Fundação Banco do Brasil, 2004; LIANZA \& ADDOR, 2005) e sobre a inserção de empreendimentos solidários em cadeias produtivas e no desenvolvimento local (PARREIRAS, 2007).

\section{Militância Acadêmica e Vigilância Epistemológica}

A Economia Solidária constitui um desses contextos investigativos em que a adesão pessoal e o lidar constante com práticas e tomadas de posição semântica e politicamente valorizadas, segundo critérios normativos da ordem do "dever ser" e das formas de intervenção, acarreta problemas de descontrolada interpenetração entre o discurso analítico, interpelador e relativista, e o discurso político, pragmático e afirmativo. Em temáticas de pesquisa dessa ordem, a reflexão teórica expõe-se continuamente à práxis militante e, nessa medida, a ficar desprovida do seu papel discriminal, em que importa tornar inconclusivos os dados imediatos da realidade e os prismas de leitura singulares, motivados por agendas políticas de intervenção, em cujos circuitos, de disputas e alianças, elaboram-se e hierarquizam-se os problemas sociais merecedores de atenção.

Exemplificando, nos dias de hoje, provavelmente não haveria desacordo em divisar quatro componentes principais na Economia Solidária: a) os empreendimentos solidários, principalmente de produção, prestação de serviços, comercialização, finanças e consumo; b) as organizações civis de apoio à Economia Solidária, contando inúmeras ONGs, universidades, entidades sindicais e organismos de pastoral social; c) os órgãos de representação e articulação política dos diversos segmentos, como os movimentos sindicais, as incubadoras, os gestores públicos, as entidades de crédito solidário e as redes de troca; d) os organismos estatais à testa dos programas públicos de apoio à Economia Solidária, específicos ou integrados a políticas transversais.

Não se têm aqui somente formas ou níveis específicos de inserção. A indistinção 
entre esses componentes como agentes sociais que integram o campo social (BOURDIEU, 1989, p. 59-73) da Economia Solidária conduz à invisibilidade das posições sociais que detêm, as quais determinam seus interesses específicos e seu papel na constituição das práticas sociais. Contudo, a noção de campo, explícita ou implicitamente, é inusual nas abordagens, que tendem a confrontar o conjunto da Economia Solidária a seus oponentes, visualizando as diferenças internas como matizes de segmentos ou setores, que partilham perspectivas convergentes e, salvo problemas localizados, irmanam esforços.

O discurso da unidade predomina politicamente. Concretizá-la constitui um desafio constante dos agentes de mediação vinculados às organizações civis e ao aparato estatal, nos quais transitam acadêmicos em formação ou já em atividade profissional. Nesse âmbito, os problemas ligados à ação e, portanto, a discussões eminentemente normativas, inerentes a políticas e programas de fomento, privilegiam certos temas, em detrimento de outros, a começar pelas políticas públicas, o que talvez explique por que, na plataforma de currículos Lattes do $\mathrm{CNPq}$, esse indexador seja um dos mais frequentes entre os pesquisadores da Economia Solidária.

Outro sintoma das interpenetrações entre as categorias da práxis política e aquelas da abordagem analítica é a facilidade com que se opera a inversão explicativa da gênese e do sentido da Economia Solidária: rapidamente equacionados no plano das questões materiais, como uma reação ao desemprego e à pauperização, tais problemas se transferem para o nível das ideias e das superestruturas, assumindo os contornos de um projeto, segundo o qual as experiências existiriam por serem iluminadas por princípios e impelidas pelo desejo de afirmá-los e disseminá-los na sociedade.

A remissão das práticas solidárias a essa noção hipostasiada e, por vezes, reificada, deixa ocultas diferenças substantivas e conduz a superestimar a função das instâncias especializadas na condução político-ideológica do campo, em detrimento dos espaços efetivos de solidariedade econômica - os empreendimentos. Esses passam a existir, no senso comum, em função e a reboque das entidades, dos programas de apoio ou das políticas públicas, consoante o projeto em vista. Além dos efeitos de enviesamento devidos à relação de forças entre os discursos que circulam no campo, concorre para isso o fato de que as motivações e atenções dos formuladores intelectuais derivam da sedução exercida pelo plano das idealizações, sobretudo quando privados de uma práxis material ela mesma solidária. $O$ efeito imediato desse autocentramento é transferir o debate precisamente para a seara da política e da ideologia, na qual os intelectuais pontificam por dever de ofício e credenciam-se continuamente.

Vale o que M. Weber ensinou-nos acerca das origens do capitalismo e o 
que E. Thompson trouxe à luz sobre a formação da classe operária: nas condições históricas concretas de sua práxis material, sem desligarem-se de suas experiências e suas contingências, os indivíduos e agrupamentos humanos movem-se de acordo com as suas aspirações, a partir das quais as necessidades ganham ou não um sentido mobilizador e algum nível de prioridade. Por conseguinte, há uma história e um ethos (GAIGER, 1997) dos trabalhadores que empreendem solidariamente, primordialmente explicativos da existência da Economia Solidária, mas fatalmente também de sua evolução e de seu declínio.

Diríamos que sobra política e faltam História e Antropologia no tratamento dessas questões. Para as formulações centradas no projeto, importa destacar e promover as práticas anticapitalistas da Economia Solidária, presumindo-se por seu sentido crítico e alternativo; para entender as razões de ser dos seus praticantes, mais sentido faria identificar as formas sociais de vida material e espiritual, não capitalistas, nas quais se enraízam as formas atuais de reciprocidade econômica e nas quais, por vezes, se reatualizam formas primárias de solidariedade (NUNES, 2001). Na falta de um olhar compreensivo, aos sujeitos em suas trajetórias e nas suas circunstâncias, finda-se em um olvido paradoxal: de que o ator popular não apenas detém a chave explicativa das razões da Economia Solidária, mas igualmente do seu desfecho e do seu sentido histórico. É Becker quem nos recorda:

Não são apenas o senso comum e os preconceitos de nossos companheiros que nos cegam para o que há para ver. Muitas vezes decidimos o que incluir e o que excluir com base num conjunto de representações e na teoria associada a elas, que decide todas essas questões para nós a priori. Todas as nossas teorias especificam alguma coisa sobre aquilo que devemos examinar e, por implicação, aquilo com que não precisamos nos incomodar (tudo aquilo com que a teoria não se incomoda). Esse é o próprio núcleo sólido das queixas feministas de que muitas, senão a maioria, de nossas teorias sociológicas são sexistas. (2007, p. 132)

A função mediadora da pesquisa e do conhecimento, para ser orgânica, necessita abordar e interpretar os problemas e dilemas das categorias sociais em tela, avaliando suas perspectivas transcendentes em bases reais, não com apriorismos teleológicos. Do contrário, reedita-se um diagnóstico sombrio, mas lapidar, sobre a incapacidade de os intelectuais, no Brasil das últimas décadas, interpretarem o mundo das classes populares e manterem unidas teoria e prática (SOUZA, 2000).

Não que objetivos políticos não impulsionem legitimamente o labor 
investigativo e devam ser (ilusoriamente) afastados. As ciências sociais e humanas não funcionam sem uma referência metacientífica fundante, crítica e projetiva quanto ao ser humano e à sociedade. Mas, no lugar de aceitar como dado que a Economia Solidária segue um desiderato determinado, caberia examinar as origens desse entendimento e tratá-lo como resultado de uma construção social, alimentada por afinidades, alianças, dissensos e conflitos, entre posições diferenciadas; por sinal, profundamente desiguais. Como demonstrado por uma tese de sociologia do conhecimento (LECHAT, 2004), foi no bojo de um processo eminentemente social que o próprio conceito de Economia Solidária foi proposto, debatido e tornado consensual no Brasil.

Assim, uma tarefa oportuna seria atentar para alguns traços do retrato da Economia Solidária tirado pelo Mapeamento, pois, embora devessem causar surpresa, não parecem despertar maior curiosidade. Contrariando as totalizações gerais pouco discriminantes, dados específicos evidenciam, por exemplo, que, proporcionalmente, as mulheres trabalham mais que os homens nos empreendimentos, conduzem por sua conta um percentual considerável de iniciativas e, nesses casos, apresentam maior envolvimento comunitário e social. Somam-se a elas outras personagens e realidades mal conhecidas, como deixa transparecer a supremacia do espaço rural na atuação dos empreendimentos e, muito em particular, a concentração notável de experiências em regiões interioranas do Nordeste, sugerindo um associativismo popular autóctone, desvinculado das estruturas locais de dominação política, que poderia representar uma vertente ignorada pelas versões centradas nas origens sulinas do associativismo e do cooperativismo no Brasil.

Outra tese corrente, já aludida, de que a Economia Solidária explica-se como uma alternativa ao desemprego, não é desmentida pelo Mapeamento, pois $45,6 \%$ dos informantes citaram ter sido esse um (não o único) dos motivos de criação dos empreendimentos; no entanto, outras motivações aparecem, tais como a busca de renda complementar $(44,1 \%)$, a obtenção de maiores ganhos (não estritamente econômicos) em um empreendimento associativo (36,9\%), o desenvolvimento de uma atividade em que todos sejam donos $(27,9 \%)$ e o desenvolvimento comunitário de capacidades e potencialidades $(13,7 \%)$. Nas entrelinhas, mais do que nos grandes números, o mapeamento sugere que a Economia Solidária responde a variadas aspirações, cevadas na inconformidade dos trabalhadores com a condição secular de subalternidade, e igualmente em sua avaliação positiva de experiências de maior autonomia, seja no contexto atual da Economia Solidária, seja naquele de outras formas de vida econômica precedentes. As preocupações com o sentido futuro da Economia Solidária centralizadas na noção de projeto - deveriam ceder passo ao estudo mais detido de suas expressões e raízes, de seu lastro e sentido desde o passado. 
Em síntese, a pesquisa requer que se tome distância, refletidamente, do campo da Economia Solidária, a fim de preservar a compreensão crítica dos processos sociais que, desde o seu interior, produzem as categorias de entendimento dos atores sociais e estipulam a hierarquia dos problemas. Dificultando a tarefa, dois obstáculos tendem a encadear-se.

Em primeiro lugar, como vimos, o caráter usualmente militante das discussões e abordagens opera uma seleção na realidade, em vista de fins e valores, com o efeito de direcionar ou prescrever o rumo dos fatos, de sorte que a exclusão de outras possibilidades facilmente alimenta um raciocínio circular, reiterativo. Instaura-se uma luta simbólica (BOURDIEU, 1989) pela representação do campo e pela designação das coisas, conferindo-lhes determinada visibilidade e relevância e, por conseguinte, chances desiguais de converterem-se em problemas de conhecimento.

As tentativas de distanciamento, por via da contextualização e pelo apelo a vertentes teóricas em si mesmas alheias ao campo presentemente em questão, esbarram, com alguma frequência, em um segundo obstáculo: tais incursões teóricas findam sendo pontuais, delimitadas ao esclarecimento dos problemas, tais como apontados pelas categorias da práxis, com isso, resumindo-se a empréstimos circunscritos que não assimilam, na sua totalidade e nas suas nuances e possíveis contradições, aquelas fontes seminais de pensamento. Autores de referência, como F. Braudel e K. Polanyi, têm sido evocados para situar o lugar histórico da Economia Solidária diante da economia de mercado, sem se evidenciar, pelo estudo sistemático daquelas obras, os seus aspectos controversos e suas incompatibilidades, no mínimo as registradas pelos próprios autores (BRAUDEL, 1998). De modo similar, ao explorarem-se as formulações de M. Mauss sobre o paradigma da dádiva, como argumento de combate à razão utilitarista e fundamento das interações humanas, em geral, e dos vínculos solidários, em particular.

Em tais casos, caberia proceder sempre a uma transposição refletida daquelas teorias, dos contextos históricos originais em que deitam seu poder explicativo para o cenário presente da economia moderna. Do contrário, pode-se enveredar por uma via ilusória - embora compreensível como uma finalidade da ação - consistindo em preconizar uma espécie de altruísmo generalizado e em banir qualquer sinal de utilitarismo. Sucumbe-se a um jogo de antípodas, irrealista (HÉNAFF, 2002), que desconhece a natureza dos vínculos sociais, inexoravelmente híbridos - feitos de dosagens variadas de solidarismo, altruísmo, pragmatismo e interesse próprio - que os indivíduos nutrem no cotidiano para gerir suas vidas, na interação com os seus círculos sociais (BAJOIT, 1992).

Ademais, conviria explorar perspectivas teóricas alheias ao circuito de 
referências dos estudos da Economia Solidária, os quais, por tratarem de determinados fenômenos em geral, são suscetíveis de aclarar sua ocorrência no caso singular das novas formas de solidariedade econômica. Formulações sobre a natureza dos vínculos sociais (BAJOIT, 1992), sobre os componentes de fruição e gratuidade nas relações humanas (OLIVEIRA, 2001) ou sobre sua presença ao longo dos tempos (DREYFUS, FLORES \& SPINOZA, 1997), possuem um valor heurístico inestimável. O mesmo pode-se dizer das reflexões sobre o lugar reservado à solidariedade no contexto social contemporâneo (D'EPINAY, 1989).

\section{Alargando a Economia}

Um recurso metodológico proporcionado por bases de dados é a proposição de modelos tipológicos, em função de algum tópico de interesse analítico, e sua posterior testagem. Tipologias não apenas retratam diferenças observadas. Sua finalidade reside em ordenar as incontáveis diferenças e similitudes perceptíveis empiricamente, hierarquizando-as de tal modo que configurem grupos representativos, dotados de singularidades que se imaginam explicativas de suas respectivas dinâmicas.

As tipologias baseiam-se, necessariamente em hipóteses sobre o que importa diferenciar, de acordo com o conhecimento prévio e com a abordagem proposta. Todavia, o intuito de separar e distinguir defronta-se com dificuldades consideráveis no caso da Economia Solidária. Em primeiro lugar, porque, nos empreendimentos, observam-se atividades econômicas simultâneas, associadas, muitas vezes, a atividades extraeconômicas, não sendo uma tarefa trivial identificar a atividade prioritária que tipificaria a natureza dos empreendimentos ou, sob outro prisma, definiria a categoria social participante. Em segundo lugar, os empreendimentos apresentam, via de regra, complexidade estrutural e funcional, pois combinam atividades coletivas e individuais, cujo valor, complementar ou essencial, pode variar para os membros. Adicionalmente, as fronteiras do econômico constituem um problema conceitual antigo, insolúvel, sendo suas delimitações habituais claramente inadequadas à economia popular (CORAGGIO, 2009).

Ainda assim, tipologias são úteis para desmembrar o que de fato é distinto, indo-se além das aparências e das nomenclaturas englobantes. Por isso, uma parcela dos dados do segundo Mapeamento Nacional está sendo coletada e será consignada de acordo com um critério tipológico: conforme a natureza da atividade econômica coletiva principal de cada empreendimento, blocos específicos de questões são aplicadas. Outras variáveis, acopladas a essa tipologia, poderão refiná-la em muitos sentidos, o que justifica alguns comentários a esse 
respeito, em seguimento às considerações anteriores.

A natureza da atividade econômica dos empreendimentos, critério tipológico básico do segundo mapeamento, relaciona-se às experiências e expectativas dos seus membros, fator explicativo primordial da dinâmica coletiva, como antes aludido. Ela reflete uma condição social prévia, à raiz do ato associativo, e repercute sobre a evolução dos empreendimentos, segundo possuam um caráter primário ou complementar, intensivo ou extensivo, permanente ou sazonal, para a vida material dos associados. Essa escolha depende do papel essencial ou subsidiário que as economias individuais mantêm ou passam a ter, na medida em que o empreendimento prospere. Ao mesmo tempo, define o quanto os associados estarão dispostos a investir, a cada passo dado em conjunto, o que pode redundar em ciclos progressivos ou estagnantes para os empreendimentos.

A questão está também vinculada à natureza irrevocável ou transitória da socialização dos meios de produção e dos compromissos mútuos contraídos entre os indivíduos, por razões objetivas e subjetivas. Por conseguinte, a natureza da atividade econômica sinaliza tanto as possibilidades vindouras quanto os antecedentes que a ela conduziram e que, talvez, expliquem a sorte futura do empreendimento de modo mais incisivo do que os eventos posteriores. Quando o empreendimento não propicia o meio de subsistência principal, importaria ter em vista a atividade econômica praticada individualmente pelos sócios, para a qual a Economia Solidária vem a representar um elemento adicional de sustentação e diante da qual se coloca em dependência direta.

Um segundo aspecto é que, ao se compararem os parâmetros do mapeamento com o perfil das iniciativas efetivamente registradas e com o andar dos fatos, podem-se identificar incongruências providenciais para o alargamento do horizonte de apreensão da Economia Solidária. A esse propósito, declara a Conferência Nacional de Economia Solidária, em 2006 (SENAES, 2007):

As manifestações da Economia Solidária são diversas, dentre as quais se destacam: coletivos informais, associações, cooperativas de produção, de trabalho, de consumo solidário ou de serviços; cooperativas sociais (pessoas com deficiência e transtorno mental); organizações e grupos de crédito solidário, bancos comunitários, fundos rotativos, cooperativas de crédito; redes de empreendimentos, produtores e consumidores; grupos e clubes de trocas solidárias e mercados de trocas solidárias com ou sem uso de moeda social; empresas recuperadas pelos trabalhadores em autogestão; cadeias solidárias de produção, comercialização e consumo; 
centrais de comercialização, iniciativas de comércio justo, organização econômica de comunidades tradicionais (quilombolas, comunidades negras, terreiros de matrizes africanas, povos indígenas, ribeirinhos, seringueiros, pescadores artesanais e outros extrativistas, etc.); cooperativas habitacionais autogestionárias; grupos culturais; agroindústrias familiares, entre outras iniciativas, seja nas áreas urbanas ou no meio rural, respeitando a questão de gênero, raça, etnia e geração. (grifos nossos)

A inclusão das atividades grifadas na Economia Solidária soa condizente, embora na base de dados do mapeamento verifique-se que menos de $2 \%$ dos empreendimentos tiveram suas atividades principais classificadas longe do campo ordinariamente considerado da economia, isto é, em áreas como educação, cultura e atividades recreativas, destacadas pela Conferência.

Essas rubricas não correspondem aos setores de produção de bens, prestação de serviços, fundos de crédito, comercialização ou consumo, como estipulava o primeiro mapeamento. Porém, todas elas constam da Classificação Nacional de Atividades Econômicas (CNAE), o que, de certo modo, constitui e, ao mesmo tempo, elucida uma aparente contradição: para uma atividade ser classificada como econômica pela CNAE, o pressuposto é que se trate de uma atividade de trabalho com vistas à produção ou oferta de bens materiais, culturais ou quaisquer outros, atividade que, desse modo, indicam o setor de atuação da empresa e a ocupação ou o meio de vida das pessoas que a integram.

Assim, nos registros oficiais, a economia não se identifica estritamente à esfera dos bens materiais, mas à existência de uma atividade laboral despendida na produção de bens necessários à satisfação de necessidades as mais diversas. Esse parece ser o entendimento implícito da Conferência Nacional, ao agregar novos segmentos sociais à Economia Solidária. Quando essa atividade é regular, representando uma alocação constante de tempo, e se realiza em organizações que atendem aos demais critérios da Economia Solidária, estaríamos diante de mais um empreendimento. Assim, os fatos e os registros oficiais alargam o foco inicial do mapeamento: se o bem produzido é material (gêneros agrícolas, manufaturados) ou imaterial (assessoria, educação), se tem a ver com a esfera da produção (onde o trabalho gera riqueza e renda) ou da reprodução (onde o trabalho repõe as suas condições, para seguir exercendo-se), se diz respeito, ainda, a necessidades consideradas essenciais (alimentação, moradia) ou não essenciais (cultura, lazer), torna-se secundário.

Essas classificações dicotômicas, ainda usuais em algumas disciplinas, há muito vêm perdendo sua força explicativa. O tempo de trabalho cada vez mais 
se sobrepõe a outros tempos e a divisão entre esfera da produção e da reprodução jamais fez maior sentido diante do holismo da economia familiar e do mosaico vasto e heterogêneo da economia popular. Excluir da Economia Solidária as necessidades imateriais e o trabalho necessário para satisfazê-las também soa extemporâneo diante da compreensão atual das aspirações humanas. Por extensão, o conceito de economia subjacente a essas novas definições abarcaria, além das ocupações relacionadas à produção em si, igualmente aquelas de distribuição, troca e consumo de bens e serviços. Ademais, não seria um entrave que tais bens e serviços não entrem no circuito de intercâmbios monetários, quando empregam trabalho voluntário não remunerado (aos olhos do mercado, um tempo de não trabalho), ou quando se destinam, primordialmente, aos seus próprios produtores, que assim dispensam a aquisição dos mesmos bens no mercado.

Esse raciocínio estende a Economia Solidária às diferentes atividades de geração de renda e, igualmente, às atividades de contenção de dispêndio de renda, por meio da oferta de bens e serviços que, de outro modo, exigiriam desembolso (energia, saúde) ou seriam inviáveis (habitação, atendimento a portadores de sofrimento psíquico). Assim, fica-se autorizado a uma interpretação mais ampla e inclusiva da natureza econômica dos empreendimentos solidários, o que predispõe a um melhor entendimento do seu caráter multifuncional, do hibridismo de suas relações e formas de agenciamento de recursos e do entrelaçamento entre suas dimensões, irredutíveis ao econômico.

\section{Considerações Finais}

Desse ponto de vista, a futura base de dados do segundo mapeamento é providencial. Além de abarcar iniciativas em um horizonte ampliado de economia, questionários complementares detalham informações sobre os integrantes dos empreendimentos e sobre as repercussões entre sua vida individual ou familiar e a experiência associativa na Economia Solidária. O primeiro, dedicado apenas aos empreendimentos formados exclusivamente por mulheres, com a finalidade de adicionar informações relativas às relações de gênero, em seus condicionantes e reflexos sobre a condição feminina. O segundo, a ser aplicado amostralmente aos membros dos empreendimentos, incidindo sobre o papel exercido pelos empreendimentos na vida dos seus integrantes, visando elucidar as circunstâncias e razões que levam determinados indivíduos a associar-se e a perseverar nessas organizações.

Esse montante de informações mostra-se bastante apropriado à abordagem dos temas já aludidos: as condições e processos de formação dos 
empreendimentos, as práticas de trabalho, o seu desempenho econômico, os seus efeitos sobre a vida material, social e política dos seus integrantes e, ain$\mathrm{da}$, a diversidade que os caracteriza, do ponto de vista de seus aspectos morfológicos e de sua racionalidade específica. A construção de tipologias, a partir de critérios atinentes à realidade endógena dos empreendimentos, mostra-se um instrumento útil, embora seu potencial quase não tenha sido utilizado pelos estudos em tela. A conjunção dessas análises com estudos qualitativos, ou sua triangulação (SANTOS, 2009), pode constituir um meio decisivo para que a compreensão da Economia Solidária não se restrinja à agenda politicamente construída ou a categorias transferidas incólumes de outras problemáticas científicas.

A questão da gênese das iniciativas de Economia Solidária é um dos problemas merecedores de atenção. Seu aspecto essencial não reside nas circunstâncias de natureza conjuntural, mas nos ativos materiais, nas disposições culturais e naqueles recursos de poder já detidos por seus protagonistas, conforme evoluem suas condições de vida e favorecem a revitalização ou adoção de práticas cooperativas, prováveis quando derivadas de uma matriz de solidarismo popular e propensas a operar sua metamorfose progressiva (GAIGER, 2004). Esse leque de práticas se amplifica quando novos empreendimentos são trazidos à Economia Solidária, fazendo-a transbordar as fronteiras convencionais do econômico. Importa diferenciar essas realidades, distinguir as categorias sociais que as promovem, discriminar tais práticas do ponto de vista do seu caráter inovador e do seu impacto sobre as formas habituais de vida dos trabalhadores.

Atentar à gênese e à diversidade de experiências conduz a relativizar a apreensão da Economia Solidária como uma totalidade alternativa ou como um projeto, fazendo ver que tal acepção encobre realidades sociais que trilharam caminhos até certo ponto independentes, havendo vertentes do solidarismo econômico ainda à margem dos circuitos políticos e intelectuais em que se opera esse tipo de conceptualização. Por isso, o olhar investigativo aqui proposto inverte alguns dos enfoques habituais: ele procura mirar a Economia Solidária de trás, isto é, do passado ao presente, antes do que do presente ao futuro; de baixo, ou seja, do protagonismo dos trabalhadores e das classes populares, antes que dos agentes ad hoc e seus espaços correlatos de atuação; de dentro, privilegiando os sistemas de vida dos indivíduos empreendedores em relação aos formatos em que suas demandas são recebidas e institucionalizadas.

Abstract: The Solidarity Economy constitutes, nowadays, a research theme whose expansion into Sociology's neighboring disciplines is clear and fruitful. In this context, in view of the new investigation alternatives brought about by the "Brazilian Solidarity Economy 
National Mapping", the article first discusses some work fronts that still deserve investigation and theoretical consolidation, within what the considered research agenda in working process. The article, then, questions the existing research pattern in this field, sustaining that its connections with the political praxis of the Solidarity Economy may result in avoiding problems and renouncing knowledge. Due to these findings, the article proposes bases for an investigative design with larger cognitive amplitude, especially regarding the recognition of the main impulsion factors of the Solidarity Economy and its irreducibility to the economic.

Keywords: Self-management, Popular Economy, Reciprocity, Solidarity, Pierre Bourdieu.

\section{Referências}

BAJOIT, G. Pour une Sociologie Relationnelle. Paris: PUF, 1992.

BECKER, H. Segredos e Truques da Pesquisa. Rio de Janeiro: Zahar, 2007.

BOURDIEU, P. O Poder Simbólico. Lisboa: DIFEL, 1989.

BRAUDEL, F. Civilização Material, Economia e Capitalismo. São Paulo: Martins Fontes, 1998.

CAILLÉ, A. Critique de la Raison Utilitaire. Paris: La Découverte, 1989.

CARNEIRO, V. Da dimensão econômica à dimensão política: a Economia Solidária sob a perspectiva do conflito social. Dissertação de Mestrado, Programa de Pós-Graduação em Ciência Política, Universidade Federal de Minas Gerais, 2006.

CORAggIO, J. L. Política Social y Economía del Trabajo. Buenos Aires - Madrid: Miño y Dávila Editores, 1999.

. (org.) ¿Qué es lo Económico? Materiales para un Debate Necesario contra el Fatalismo. Buenos Aires: CICCUS, 2009.

CATTANI, A. et al. Dicionário Internacional da Outra Economia. Coimbra: Almedina, 2009.

COUTROT, T. Critique de l'Organisation du Travail. Paris: La Découverte, 1999.

DEFOURNY, J. “Coopératives de Production et Entreprises Autogérées: une Synthèse du Débat sur les Effets Economiques de la Participation". Mondes en Développement, vol. 16, no 61, 1988, p. 139-153. 
DEFOURNY, J.; DEVELTERE, P.; FONTENEAU, B. (Eds.) L'Economie Sociale au Nord et au Sud. Paris - Bruxelles: De Boek, 1999.

D'EPINAY, C. "Individualisme et Solidarité aujourd'hui". Cahiers Internationaux de Sociologie, vol. 86, 1989, p. 15-32.

DOIMO, A. M. A Vez e a Voz do Popular. Rio de Janeiro: Relume Dumará, 1995.

DREYFUS, H.; FLORES, F.; SPINOSA, C. Disclosing New Worlds: Entrepreneurship, Democratic Action and the Culivation of Solidarity. Cambridge: MIT Press, 1977.

FERRARINI, A.; GAIGER, L. "Quando o Micro não é Sinônimo de Pequeno: a Vertente Metautilitarista do Empreendedorismo". Otra Economía, vol. IV, no 7, 2010, p. 84-100.

FONTENEAU, B. et al. Economía Social y Solidaria: Nuestro Camino Común hacia el Trabajo Decente. Turin: Centro Internacional de Formación de la OIT, 2011.

FUNDAÇÃO BANCO DO BRASIL (Org.) Tecnologia social: uma estratégia para o desenvolvimento. Rio de Janeiro, 2004.

GAIGER, L. "Ethos de Posição e Vida Cotidiana". Revista Estudos Leopoldenses, vol. 33, no 151, 1997, p. 69-94.

. (org.) Sentidos e Experiências de Economia Solidária. Porto Alegre:

UFRGS, 2004.

. "A Economia Solidária e o Valor das Relações Sociais Vinculantes". Katálysis, vol. 11, no 1, 2008, p. 11-19.

. "Posfácio: Contribuições para uma Agenda de Pesquisa", in P. Hespanha e A. Santos (orgs.), Economia Solidária: Questões Teóricas e Epistemológicas. Coimbra: Almedina, 2011.

- "A Presença Política da Economia Solidária. Considerações a partir o Primeiro Mapeamento Nacional", In: I. Georges e M. Leite (orgs.), Novas Configurações do Trabalho e Economia Solidária. São Paulo: Annablume, 2012.

GODBOUT, J. O Espírito da Dádiva. Rio de Janeiro: Fundação Getúlio Vargas, 1999.

HÉNAFF, M. Le Prix de la Vérité; le Don, l'Argent, la Philosophie. Paris: Seuil, 2002. 
LAVILLE, JL.; GAIGER, L. “Economia Solidária”, In: A. Cattani et al. (orgs.), Dicionário Internacional da Outra Economia. Coimbra: Almedina, 2009.

LECHAT, N. Trajetórias Intelectuais e o Campo da Economia Solidária no Brasil. Tese de Doutorado, Programa de Pós-Graduação em Sociologia, Universidade Estadual de Campinas, 2004.

LIANZA, S.; ADDOR, F. (orgs.) Tecnologia e Desenvolvimento Social e Solidário. Porto Alegre: UFRGS, 2005.

LIMA, J. “Cooperativas, trabalho associado, autogestão e Economia solidária: a constituição do campo de pesquisa no Brasil", In: I. Georges e M. Leite (orgs.), Novas Configurações do Trabalho e Economia Solidária. São Paulo: Annablume, 2012.

MENDEL, M. “La Aparición de Movimientos Sociales Internacionales y la Economía Social y Solidaria”. Économie et Solidarités, número especial, 2003, p. 19-29.

MIRANDA, D. A Democracia Dialógica: uma Análise das Iniciativas da Economia Solidária. Tese de Doutorado, Programa de Pós-Graduação em Ciências Sociais. Universidade do Vale do Rio dos Sinos, 2011.

NUNES, C. "Cooperativas, uma Possível Transformação Identitária para os Trabalhadores do Setor Informal". Sociedade \& Estado, vol. 16, no 1/2, 2001, p. 134-158.

OLIVEIRA, P. (org.) O Lúdico na Cultura Solidária. São Paulo: Hucitec, 2001.

PARREIRAS, L. E. Negócios Solidários em Cadeias Produtivas: Protagonismo Coletivo e Desenvolvimento Sustentável. Rio de Janeiro: IPEA, 2007.

PETITCLERC, M. "Nous Protégeons I'Infortune» Les Origines Populaires de I'Économie Sociale au Québec. Montreal : VLB Éditeur, 2007.

PINTO, J. R. Economia Solidária; de Volta à Arte da Associação. Porto Alegre: UFRGS, 2006.

POLANYI, K. A Grande Transformação. Rio de Janeiro: Campus, 1988.

RAZETO, L. Los Caminos de la Economía de Solidaridad. Buenos Aires: LumenHvmanitas, 1997 
ROTHSCHILD, J.; WHITT, J. A. The Cooperative Workplace: Potentials and Dilemmas of Organisational Democracy and Participation. Cambridge: Cambridge University Press, 1986.

SANTOS, T. "Do Artesanato Intelectual ao Contexto Virtual: Ferramentas Metodológicas para a Pesquisa Social". Sociologias, vol. 11, no 21, 2009, p. 120-156.

SENAES. O Processo de Construção da Base Conceitual do SIES; Subsídios para a Comissão Gestora Nacional. Brasília: Ministério do Trabalho e Emprego, 2007.

SINGER, P. Uma Utopia Militante (2a ed.). Petrópolis: Vozes, 1999.

SOCIEDADE \& ESTADO (2001) Dádiva e Solidariedades Urbanas, vol. XVI, № 1-2, Brasília: Universidade de Brasília.

SOUZA, L. A. "Um País Dinâmico, um Pensamento Claudicante". Estudos Avançados, vol. 14, no 40, 2000, p. 77-90. 